\title{
Validated spectrophotometric method for analysis of dipyridamole and Lamivudine using eosin Y.
}

\author{
Sona B. Soliman*1, Sawsan Abd El-Razeq ${ }^{1}$, Mohamed El -Awady², Fathalla Belal ${ }^{2}$
}

${ }^{1}$ Department of Pharmaceutical Analytical Chemistry, Faculty of Pharmacy, Al-Azhar University, Cairo, Egypt.

${ }^{2}$ Department of Analytical Chemistry, Faculty of Pharmacy, Mansoura University, Mansoura, Egypt.

*Correspondence: suna soliman@yahoo.com

\begin{abstract}
Article history: Received 12-12-2020 Revised 28-12-2020 Accepted 07-01-2021
Abstract: Validated, accurate, simple and reliable spectrophotometric method was described for the assay of dipyridamole and lamivudine in their different dosage forms. The suggested method depended on a binary reddish orange coloured complex formation between eosin $\mathrm{Y}$ and each one of the two analytes in presence of carboxy methyl cellulose and aqueous buffered medium for dipyridamole and lamivudine, respectively at $\mathrm{pH}$ 3.7. The coloured binary complexes exhibited maximum absorbance at $554.0 \mathrm{~nm}$ for dipyridamole and lamivudine. The absorbance concentration graphs were linear over ranges of $(1.0-10.0 \mu \mathrm{g} / \mathrm{mL})$ and $(2.0-20.0$ $\mu \mathrm{g} / \mathrm{mL}$ ), with lower detection limits of $0.27 \mu \mathrm{g} / \mathrm{mL}$ and $0.46 \mu \mathrm{g} / \mathrm{mL}$ and lower quantitation limits of 0.82 $\mu \mathrm{g} / \mathrm{mL}$ and $1.40 \mu \mathrm{g} / \mathrm{mL}$ for dipyridamole and lamivudine, respectively. The developed method was applicable to the assay of dipyridamole and lamivudine in their different dosage forms, and the obtained results were in acceptable agreement with all those provided by reference methods. The present method is appropriate for the assay of the two drugs on account of its cost effectiveness, simplicity and rapidity.
\end{abstract}

Keywords: Spectrophotometric; Dipyridamole; Lamivudine, Eosin Y; Dosage Forms.

\section{INTRODUCTION}

Dipyridamole (DPD) is in a class of drugs called antiplatelet agents, it works by preventing excessive blood clotting, Figure 1 illustrates its chemical structure. DPD is a pyramidopyrimidine compound that modestly decreases platelet activity by acting as a phosphodiesterase inhibitor. It also has significant endothelial activity and functions as a vasodilator. DPD prevents the endothelium attachment of platelets and it is an inhibitor of adenosine reuptake. It is used in thromboembolic disorders and in the management of stroke. Oral DPD is used for the prophylaxis of thromboembolism after cardiac valve replacement; it also has been used in the management of myocardial infarction $^{1}$. DPD is indicated as, anti-anginal, antithrombotic for prostatic valves and also indicated in case of pulmonary hypertension. It is unlikely to lead to a lasting decrease in blood pressure and this may explain why strokes rather than coronary events may be avoided by this drug. For infants, DPD is often prescribed to treat a rare condition called Kawasaki disease $^{2}$. By reviewing the literature review, DPD was determined either singly or in combination with other drugs in their dosage forms by spectrophotometric ${ }^{3,4}$, spectrofluorimetric $^{5}$ electrochemical ${ }^{6}$ and HPLC methods $^{7,8}$.

Lamivudine (LMV) is in a class of drugs known as reverse transcriptase nucleoside inhibitors. LMV must be intracellularly converted to its triphosphate form, which then competes for incorporation into the developing viral DNA strand with cytosine triphosphate. This results in chain termination and prevents the replication of viral DNA. It works by reducing the amount of hepatitis B virus and HIV in the blood, so it has activity against hepatitis B and human immunodeficiency viruses. In addition to, it has been used with other antiviral drugs for the treatment of human immunodeficiency virus infections 9 . Furthermore, LMV is active against a human immunodeficiency virus resistant to zidovudine. ${ }^{10}$ Chemical structure of LMV is illustrated in Figure 1. By reviewing the literature review, LMV was determined either singly or in combination with other drugs in their dosage forms. Examples of the reported methods, spectrophotometric 11,12 , HPLC 13,14, and capillary electophoretic methods ${ }^{15,16}$.

Eosin $\mathrm{Y}$ is a xanthene dye commonly used for assaying many pharmaceutical compounds. As it has a single carboxyl group, it is known as an acidic dye. It is able to form ion-pair complexes with basic drugs in acid medium, this resulted in a major bathochromic

Cite this article: Barghash, S., Abd El-Razeq, S., El -Awady, M., Belal, F. Validated Spectrophotometric method for analysis of Dipyridamole and Lamivudine using eosin Y. Azhar International Journal of Pharmaceutical and Medical Sciences, 2021; 1(1): 73-82. doi: 10.21608/aijpms.2021.52761.1016

DOI: 10.21608 /aijpms.2021.52761.1016 
shift in the dye's original UV-VIS spectrum or even a quenching effect on its native fluorescence spectrum that was then used for analytical purposes. The complexes formed between numerous pharmaceutical components and eosin $\mathrm{Y}$ for their spectrofluorimetic or spectrophotometric assay has been always investigated ${ }^{17-19}$. The method described is designed to study the binary complex formation between DPD or LMV and eosin $\mathrm{Y}$ in a trial to develop an easy, sensitive, lower-cost and accurate spectrophotometric method for analysis of DPD and LMV in their dosage forms.

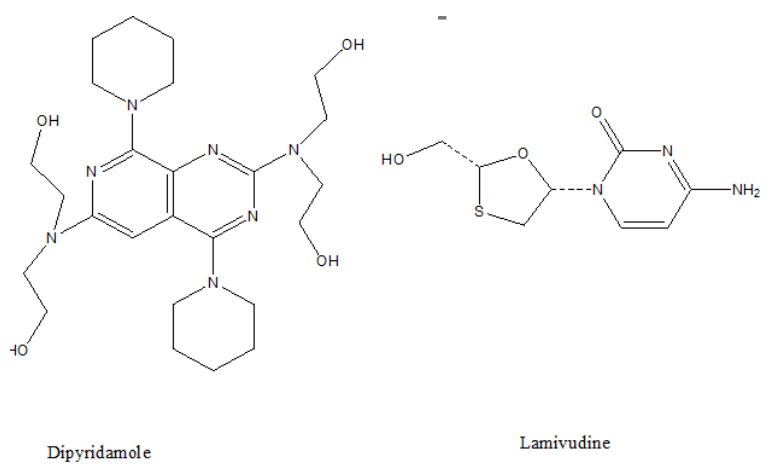

Figure (1): Chemical structure of Dipyridamole and Lamivudine, DPD; Chemical Formula: C24H40N8O4, Molecular Weight $=504.63$. LMV; Chemical Formula: C8H11N3O3S, Molecular Weight $=229.3$.

\section{METHODS}

\subsection{Instrument}

Shimadzu (Kyoto, Japan) UV-1601 PC, UV-Visible double-beam spectrophotometer was operated on a fast scan speed. For adjusting the $\mathrm{pH}, \mathrm{A}$ HANNA $\mathrm{pH}-$ meter (Romania) was used.

\subsection{Materials and reagents}

Pure DPD was supplied by the Chemical Industries Development (CID) company, Giza, Egypt. (certified to have purity of $99.97 \%$ ). Pure LMV was kindly provided by EVA PHARMA for Pharmaceuticals Medical Appliances S.A.E., Kafr El Gabal-Haram, Giza , Egypt. (certified to have a purity of 99.99\%). DPD and LMV dosage forms were purchased from local pharmacies: Persantin ${ }^{\circledR}$ Tablets (batch \# 103030), containing $75 \mathrm{mg}$ of DPD/tablet. Lamidine ${ }^{\circledR}$ Tablets (batch \# 402336), containing $150 \mathrm{mg}$ of LMV/tablet. All reagents used were of analytical grade. During the work, distilled water was used and the solvents were of spectroscopic grade: Eosin Y was purchased from (Merck, Darmstadt, Germany). Solutions of Eosin $\left(2 \times 10^{-3} \mathrm{M}\right)$ and $\left(4 \times 10^{-3} \mathrm{M}\right)$ were prepared by dissolving $0.14 \mathrm{gm}$ or $0.28 \mathrm{gm}$ in $100 \mathrm{~mL}$ distilled water, respectively. Anhydrous sodium acetate together with acetic acid were obtained from (Merck, Darmstadt, Germany). The required $\mathrm{pH}$ value was obtained through mixing appropriate volumes of $(0.2 \mathrm{M})$ acetic acid and $(0.2 \mathrm{M})$ sodium acetate solutions to prepare $0.2 \mathrm{M}$ acetate buffer .20 Surfactants: Citrimide, Sodium dodecyle sulphate (SDS), CMC, Tween 80, Concentrated sulfuric acid $\mathrm{H}_{2} \mathrm{SO}_{4}$ (99\% purity) were obtained from El-Nasr Pharmaceutical Chemicals Company (ADWIC), Abu Zaabal, Egypt. $0.1 \% \mathrm{w} / \mathrm{v}$ aqueous solution of carboxy methyl cellulose (CMC) was prepared.

\subsection{Standard solutions}

Standard solutions $(100.0 \mu \mathrm{g} / \mathrm{mL})$ of DPD and LMV were prepared separately in $0.05 \mathrm{M} \mathrm{H}_{2} \mathrm{SO}_{4}$ and distilled water for DPD and LMV, respectively and further dilution was made as appropriate using the same solvent.

\subsection{Procedures}

\subsubsection{Construction of the calibration curves}

For DPD, accurate volumes of the stock solution in concentration range $(10.0-100.0 \mu \mathrm{g} / \mathrm{mL})$ of drug were transferred into a set of volumetric flasks measures 10 $\mathrm{mL}$. To each flask, $2 \mathrm{~mL}$ of $(0.1 \%) \mathrm{CMC}$ and $2 \mathrm{~mL}$ of $\left(2 \times 10^{-3} \mathrm{M}\right)$ eosin $\mathrm{Y}$ were added and mixed well. Then, each flask was completed by the addition of $(0.2 \mathrm{M})$ acetate buffer ( $\mathrm{pH} 3.7)$.

For $L M V$, accurate volumes of the stock solution in concentration range $(20.0-200.0 \mu \mathrm{g} / \mathrm{ml})$ of drug were transferred into a set of volumetric flasks measures 10 $\mathrm{mL}$. To each flask, $4 \mathrm{~mL}$ distilled water and $1 \mathrm{~mL}$ of (4x10-3 M) eosin $\mathrm{Y}$ were added and mixed well. Then, each flask was completed by the addition of $(0.2 \mathrm{M})$ acetate buffer ( $\mathrm{pH} 3.7)$.

For DPD and $L M V$, the absorbance of each concentration was measured at $554.0 \mathrm{~nm}$ against a suitable blank and absorbance was plotted versus the final drug concentration in $\mu \mathrm{g} / \mathrm{mL}$ and the regression equations were derived.

\subsubsection{Applications to dosage forms}

Ten tablets (Persantine $75 \mathrm{mg}$ or Lamidine $150 \mathrm{mg}$ tablets) were weighted, finely powdered and thoroughly mixed well; then an exactly weighed quantity of the powder equivalent to $10.0 \mathrm{mg}$ of DPD or LMV were transferred into $100 \mathrm{~mL}$ volumetric flasks, and extracted with $75 \mathrm{~mL}$ of $0.05 \mathrm{M} \mathrm{H}_{2} \mathrm{SO}_{4}$ or distilled water for DPD or LMV, respectively. The flasks were subjected to sonication for $30 \mathrm{~min}$ and completed with the suitable solvent then filtered. The obtained solutions claimed to contain $100 \mu \mathrm{g} / \mathrm{mL}$ of 
each drug then analyzed adopting the procedures previously mentioned under " Construction of the Calibration curves ". From the corresponding regression equation, the nominal content of tablets was estimated.

\section{RESULTS AND DISCUSSION:}

The aim of this research was to develop an uncomplicated and estimable spectrophotometric method without the need of prior extraction for the estimation of DPD and LMV in their dosage forms. DPD and LMV were found in this study to form an ion pair reddish orange complexes with eosin $\mathrm{Y}$ at $\mathrm{pH} 3.7$ with $\lambda \max 554.0 \mathrm{~nm}$ for both drugs; Figure 2. The formed complexes are chiefly due to the electrostatic interaction under acidic $\mathrm{pH}$ between the cationic drugs and the anionic functional group of eosin.

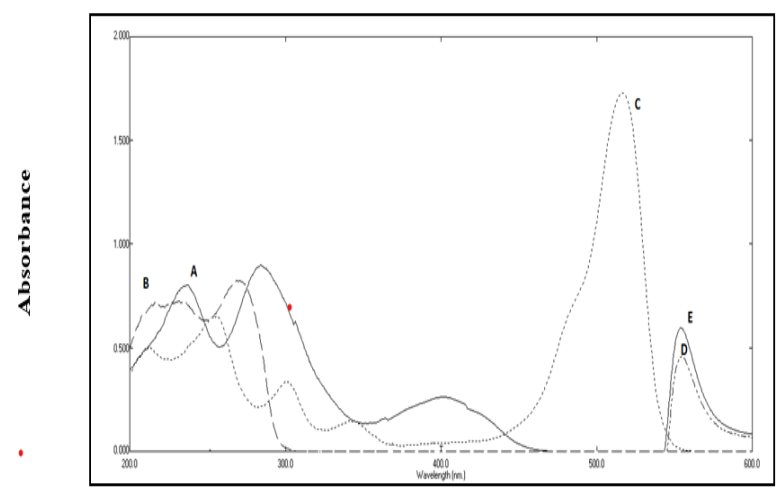

Figure (2): Absorption spectra of: (A) DPD in 0.05 $\mathrm{MH}_{2} \mathrm{SO}_{4}(5 \mu \mathrm{g} / \mathrm{mL})$. (B) LMV in water $(8 \mu \mathrm{g} / \mathrm{mL})$. (C) Blank eosin $\mathrm{Y}\left(4 \times 10^{-3} \mathrm{M}\right)$ in water. (D) Eosin $\mathrm{Y}$ binary complex with lamivudine $(10 \mu \mathrm{g} / \mathrm{mL})$ at $\mathrm{pH} 3.7$. (E) Eosin $\mathrm{Y}$ binary complex with dipyridamole $(7 \mu \mathrm{g} / \mathrm{mL})$ at $\mathrm{pH} 3.7$.

\subsection{Optimization of the reaction conditions}

pH: Over the $\mathrm{pH}$ range (3.6-5.5), the impact of $\mathrm{pH}$ on the absorbance intensity of the formed complexes was investigated. It was noticed that, the values of optimum absorbance for both drugs were achieved at $\mathrm{pH}$ 3.7.; Figure 3. Volume of eosin $Y$ reagent: Various volumes of $\left(2 \times 10^{-3} \mathrm{M}\right)$ and $\left(4 \times 10^{-3} \mathrm{M}\right)$ eosin $\mathrm{Y}$ solution were added to DPD and LMV respectively to assess the optimum reagent volume. 1.5-2.5 mL for DPD and $0.5-1.5 \mathrm{~mL}$ for LMV were found to be sufficient to give maximum color intensity. Thus $2 \mathrm{~mL}$ and $1 \mathrm{~mL}$ of eosin solution were used for DPD and LMV, respectively. Lower volumes showed decreased absorbance; Figure 4.

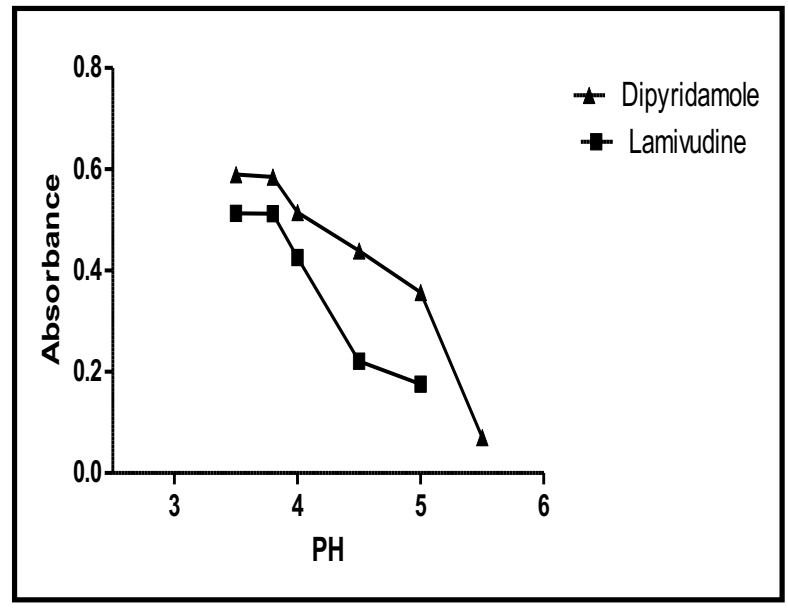

Figure (3): Effect of $\mathrm{pH}$ of $0.2 \mathrm{M}$ acetate buffer on the absorbance value of $7 \mu \mathrm{g} / \mathrm{mL}$ and $10 \mu \mathrm{g} / \mathrm{mL}$ for Dipyridamole and Lamivudine with eosin $\mathrm{Y}\left(2 \times 10^{-3} \mathrm{M}\right)$ and $\left(4 \times 10^{-3} \mathrm{M}\right)$ respectively.

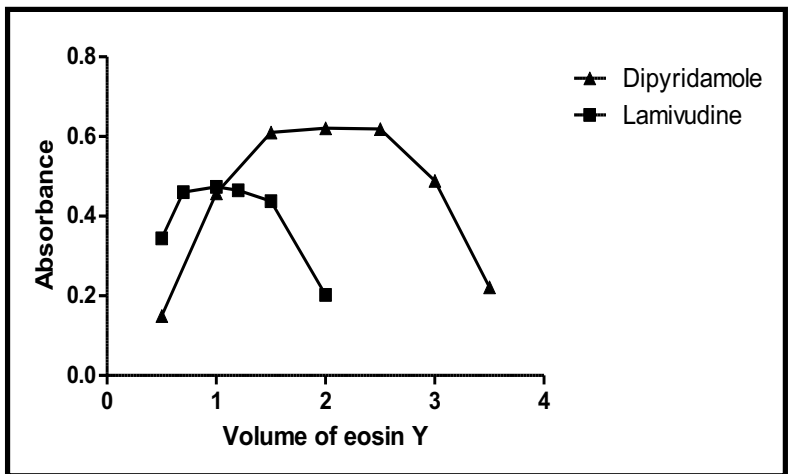

Figure (4): Effect of volume of eosin $\left(2 \times 10^{-3} \mathrm{M}\right)$ and $\left(4 \times 10^{-3} \mathrm{M}\right)$ on the absorbance value of product with $7.0 \mu \mathrm{g} / \mathrm{mL}$ and10 $\mu \mathrm{g} / \mathrm{mL}$ for DPD and LMV respectively.

Effect of surfactant: The slight solubility of eosin Y complexes with drugs in aqueous acidic solutions amounted to either extraction with organic solvent ${ }^{21}$ or addition of nonionic surfactant namely methyl cellulose, SDS, tween 80 and Cetrimide to stabilize and solubilize the resulted complex 22,23 . Consequently, several trials have been carried out to solve this problem, where the previously mentioned surfactants were tried. SDS and Cetrimide showed decreased absorbance while tween 80 and methyl cellulose were attempted to prevent precipitation of the complex. Methyl cellulose was the best giving good reliability results, hence $0.1 \%$ of its aqueous solution was used where maximum absorbance was achieved using $2.0 \pm$ $0.2 \mathrm{~mL}$ of $0.1 \%$ methyl cellulose for DPD; Figure 5 . 
However, the reproducibility was adversely affected in case of LMV. Consequently, the method reported by El-Brashy et $\mathrm{al}^{24}$ was applied in case of LMV. This method was based on preserving the maximum dilution of the drug before adding the dye solution and mixing well before adding the acidic buffer. The complex stability was significantly improved by following this technique and prevention of precipitate formation was achieved.

Temperature: For both drugs, it was noticed that, at room temperature, the absorbance was optimum; increasing the temperature led to precipitate formation that could be due to the coagulation of the resulted complex.

Time:the influence of time on the development and sta bility of the resulted complex has been studied and it has been found that the complex is instantly formed and found to be stable for 2 hours and the complex did not precipitate.

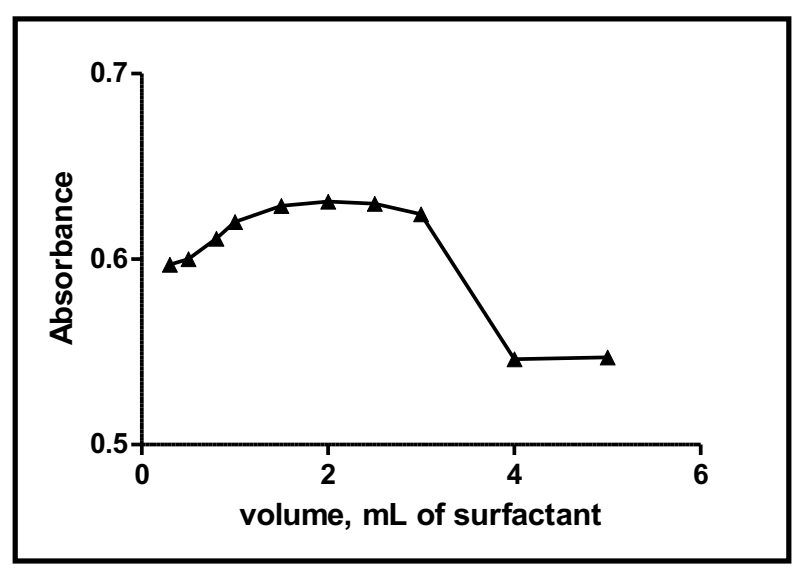

Figure (5): Effect of volume of methyl cellulose on the absorbance of the reaction product of $7.0 \mu \mathrm{g} / \mathrm{mL}$ DPD with Eosin Y $\left(2 \times 10^{-3} \mathrm{M}\right)$.

\subsection{Stoichiomery of the reaction}

These complexes are formed due to electrostatic interaction between carboxylate anion of the dye and the most basic center (amino group) in the drug molecule. Using Job's Method ${ }^{25}$ (Figure 6), the reaction was found to be in the ratio of 1:2 of the drug to eosin for DPD because it has two basic centers and 1:1 for LMV as it has one basic center. Figure 7 indicates the proposed reaction pathway mechanism.

\subsection{Validation of the developed method}

The suggested method was validated regarding the guidelines stated by International Conference of Harmonization (ICH) Q2 (R1) ${ }^{26}$.

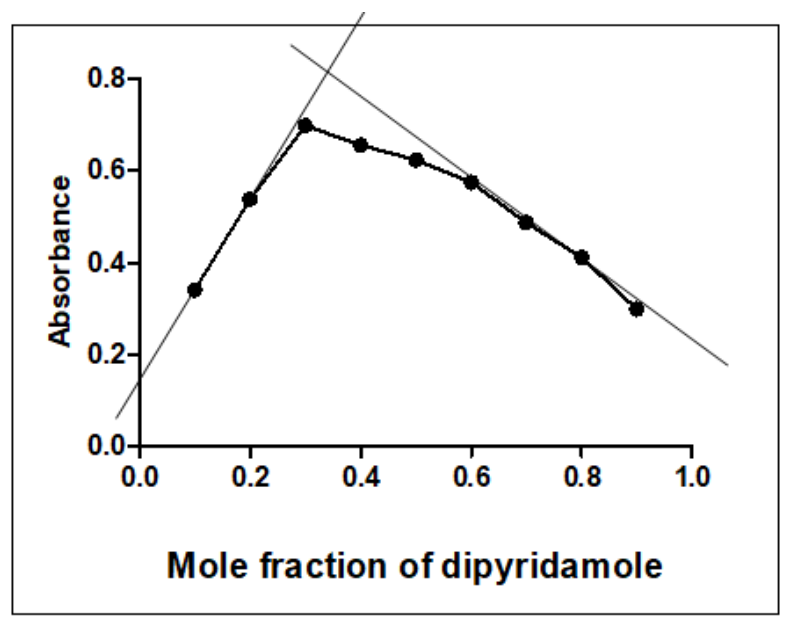

Figure (6) A: Stoichiometry of the reaction of (A) Dipyridamole with eosin Y $\left(2.0 \times 10^{-3} \mathrm{M}\right)$ by Job's method.

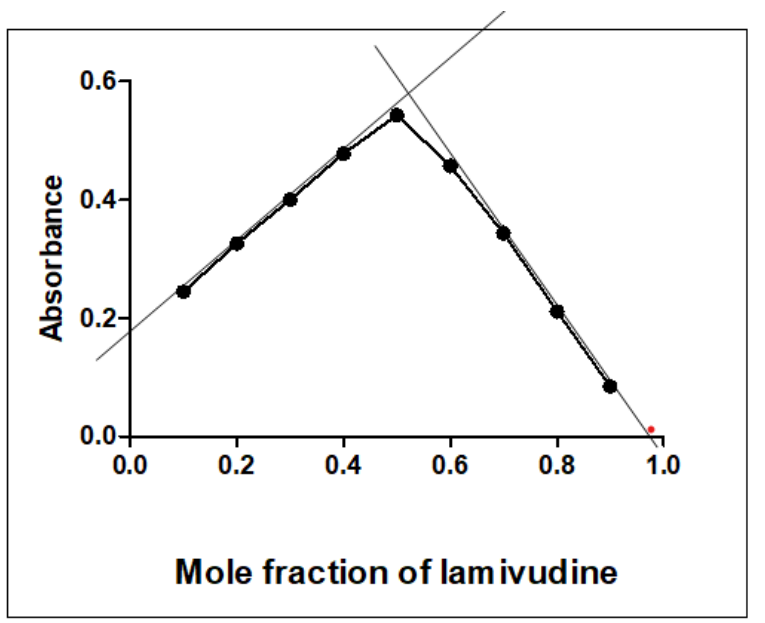

Figure (6) B: Stoichiometry of the reaction of (B) Lamivudine with eosin Y $\left(4.0 \times 10^{-3} \mathrm{M}\right)$ by Job's method.

\subsection{Linearity}

Linear relationship was found to exist between the absorbance values and the corresponding drugs concentration over the range of (1.0-10.0) ug/ml and (2.0-20.0) ug / $\mathrm{ml}$ for DPD and LMV respectively;

Table 1 .

3.5. Limit of detection (LOD) and limit of quantification (LOQ):

LOD and LOQ were determined as stated by ICH $\mathrm{Q} 2(\mathrm{R} 1)$ recommendations ${ }^{26}$. LOD was found to be $(0.27 \mu \mathrm{g} / \mathrm{mL})$ for DPD and $(0.46 \mu \mathrm{g} / \mathrm{mL})$ for LMV, while LOQ was found to be $(0.82 \mu \mathrm{g} / \mathrm{mL})$ and $(1.40$ $\mu \mathrm{g} / \mathrm{mL}$ ) for DPD and LMV, respectively; Table 1 . 


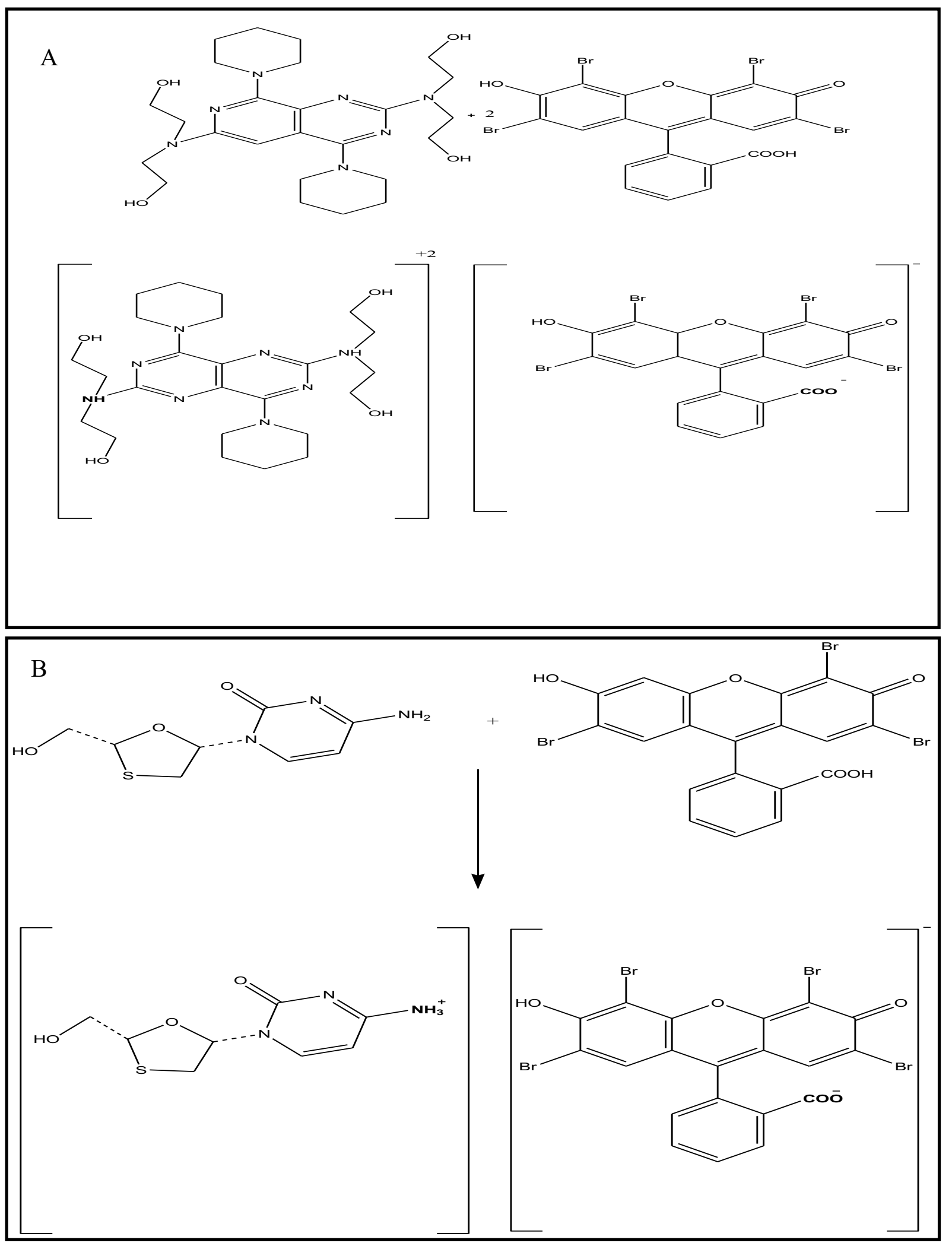

Figure (7): Proposed mechanisms for the reaction between eosin Y, (A) Dipyridamole, (B) Lamivudine 
Table (1): Analytical performance data for the determination of the studied drugs by the proposed method.

\begin{tabular}{|c|c|c||}
\hline Parameter & Dipyridamole & Lamivudine \\
\hline $\begin{array}{c}\text { Linearity range } \\
\left(\mu \mathrm{g} \mathrm{mL}^{1}\right)\end{array}$ & $(1.0-10.0)$ & $(2.0-20.0)$ \\
\hline Intercept \pm S.D & $0.022 \pm 7.120 \times 10-3$ & $0.027 \pm 6.265 \times 10-3$ \\
\hline Slope \pm S.D & $0.087 \pm 1.140 \times 10-3$ & $0.045 \pm 5.102 \times 10-4$ \\
\hline Correlation coefficient $(\mathbf{r})$ & 0.9997 & 0.9998 \\
\hline SD of residuals $\left(\mathrm{S}_{\mathrm{y} / \mathbf{x}}\right)$ & $0.91 \times 10-2$ & $7.45 \times 10-3$ \\
\hline$($ LOD $)\left(\mu \mathrm{g} \mathrm{mL}^{-1}\right.$ & 0.27 & 0.46 \\
\hline$($ LOQ $)\left(\mu \mathrm{gL}^{-1}\right)$ & 0.82 & 1.40 \\
\hline
\end{tabular}

\subsection{Precision}

Evaluation of the intra-day or interday precision of the present method was carried out by analyzing three concentrations of DPD and LMV in raw materials in the same day or over three consecutive days, respectively. The small values of ( $\%$ RSD) ranged from 0.78 to $1.61 \%$ and 0.80 to $1.35 \%$ for DPD and LMV respectively; indicate reasonable repeatability, high precision and accuracy of the present method, Table 2.

\subsection{Accuracy}

The results of the proposed method were compared to those obtained using the reference methods 27,28 to validate the accuracy of the proposed method, The first one $^{27}$ is the official HPLC method to determine DPD using C18 column, phosphate buffer : methanol (30:70) of $\mathrm{pH} 4.6$ was used as mobile phase and UV detection at $288.0 \mathrm{~nm}$.
The second one is spectrophotometric method to determine LMV which based on direct spectrophotometric measurement of LMV solution at $280.0 \mathrm{~nm}$ in water ${ }^{28}$. Statistical analysis ${ }^{29}$ of the results using student's t-Test and variance ratio F-test showed no significant differences between them regarding accuracy and precision, respectively, Table 3.

\subsection{Robustness}

Method robustness was determined by the resistance of the proposed method to deliberate minor change in the parameters of the experiment such as the change of eosin Y volume $(2.0 \pm 0.2)$ and $(1 \pm 0.2)$ for DPD and LMV respectively. The absorption intensity was not affected by these minor changes, proved good robustness of the developed method.

Table (2): Precision data for the determination of the studied drugs by the proposed method.

\begin{tabular}{|c|c|c|c|c|c|c|c|}
\hline \multirow{2}{*}{\multicolumn{2}{|c|}{ Parameters }} & \multicolumn{3}{|c|}{ Dipyridamole $(\mu \mathrm{g} / \mathrm{mL})$} & \multicolumn{3}{|c|}{ Lamivudine $(\mu \mathrm{g} / \mathrm{mL})$} \\
\hline & & 2.0 & 8.0 & 10.0 & 2.0 & 10.0 & 20.0 \\
\hline \multirow{6}{*}{ Intraday $^{a}$} & \multirow{3}{*}{$\%$ Found } & 99.01 & 97.09 & 98.58 & 98.43 & 99.42 & 97.16 \\
\hline & & 98.50 & 99.35 & 99.78 & 97.64 & 98.84 & 98.18 \\
\hline & & 97.03 & 98.54 & 100.11 & 99.21 & 97.38 & 99.43 \\
\hline & Mean & 98.18 & 98.33 & 99.49 & 98.42 & 98.55 & 98.26 \\
\hline & \%RSD & 1.05 & 1.17 & 0.81 & $\mathbf{0 . 8 0}$ & 1.06 & 1.16 \\
\hline & \%Error & 0.61 & 0.67 & 0.47 & 0.46 & 0.61 & 0.67 \\
\hline \multirow{6}{*}{ Interday $^{b}$} & \multirow{3}{*}{$\%$ Found } & 98.02 & 99.19 & 99.89 & 99.21 & 99.71 & 98.86 \\
\hline & & 100.49 & 98.87 & 98.47 & 100.79 & 98.55 & 97.50 \\
\hline & & $\mathbf{9 7 . 5 3}$ & 97.73 & 97.92 & 98.11 & 97.67 & 99.77 \\
\hline & Mean & 98.68 & 98.60 & 98.76 & 99.37 & 98.64 & 98.71 \\
\hline & \%RSD & 1.61 & 0.78 & 1.03 & 1.35 & 1.04 & 1.16 \\
\hline & \%Error & 0.93 & 0.45 & 0.60 & 0.78 & 0.60 & 0.67 \\
\hline
\end{tabular}

Each result is the average of three separate determinations. ${ }^{a}$ Within the day ${ }^{\mathrm{b}}$ Three consecutive days. 


\subsection{Specificity}

Method specificity was assessed by the absence of interference from the common excipients of the dosage forms during analysis; Table 4.

\subsection{Applications}

The developed method was successfully used to assay DPD and LMV in their different dosage forms. Statistical comparison of the obtained results to the reported methods ${ }^{27,28}$ was performed applying t-test and F-test ${ }^{29}$. The results obtained proved excellent accuracy and precision of the developed method; Table 4.

\section{CONCLUSION}

To determine DPD and LMV in their dosage forms, an accurate and simple visible spectophotometric method was developed through water soluble ion- pairing complex with eosin Y. In this method; no need to use organic solvents which makes the proposed method environmentally friendly.

The advantages of this method were its simplicity, timesaving and non- requiring various elaborate treatments or boring methods for extraction, which make the developed method appropriate in quality control laboratories for routine analysis.

Table (3): Assay results for the determination of Dipyridamole and Lamivudine in pure form by the proposed and comparison methods ${ }^{27,28}$.

\begin{tabular}{|c|c|c|c|c|c|c|}
\hline \multirow{2}{*}{ Ranges } & \multicolumn{3}{|c|}{ Proposed Method } & \multicolumn{3}{|c|}{ Comparison methods ${ }^{27,28}$} \\
\hline & $\begin{array}{c}\text { Taken } \\
(\mu \mathrm{g} / \mathrm{mL})\end{array}$ & $\begin{array}{c}\text { Found } \\
(\mu \mathrm{g} / \mathrm{mL})\end{array}$ & \% Recovery & $\begin{array}{c}\text { Taken } \\
(\mu \mathrm{g} / \mathrm{mL})\end{array}$ & $\begin{array}{c}\text { Found } \\
(\mu \mathrm{g} / \mathrm{mL})\end{array}$ & \% Recovery \\
\hline \multirow{6}{*}{ Dipyridamole } & 1.00 & 1.03 & 103.00 & 5.00 & 4.88 & 97.60 \\
\hline & 2.00 & 2.02 & 101.00 & 10.00 & 10.24 & 102.40 \\
\hline & 4.00 & 3.98 & 99.50 & 15.00 & 14.88 & 99.20 \\
\hline & 7.00 & 6.98 & 99.71 & & & \\
\hline & 8.00 & 7.85 & 98.13 & & & \\
\hline & 10.00 & 10.13 & 101.30 & & & \\
\hline Mean \% & & & 100.44 & & & 99.73 \\
\hline \pm S.D. & & & 1.57 & & & 2.43 \\
\hline t-test & \multicolumn{6}{|c|}{$0.470(2.360)$} \\
\hline F-test & \multicolumn{6}{|c|}{$2.41(5.79)$} \\
\hline \multirow{5}{*}{ Lamivudine } & 2.00 & 2.02 & 101.00 & 2.00 & 1.94 & 97.00 \\
\hline & 5.00 & 5.07 & 101.40 & 4.00 & 4.09 & 102.25 \\
\hline & 10.00 & 9.67 & 96.70 & 8.00 & 7.97 & 99.63 \\
\hline & 15.00 & 14.9 & 99.33 & & & \\
\hline & 20.00 & 19.9 & 99.50 & & & \\
\hline Mean \% & & & 99.59 & & & 99.62 \\
\hline \pm SD & & & 1.86 & & & 2.56 \\
\hline t-test & \multicolumn{6}{|c|}{$0.019(2.447)$} \\
\hline F-test & \multicolumn{6}{|c|}{$1.88(6.94)$} \\
\hline
\end{tabular}

Each result is the average of three separate determinations.

The values between parentheses are the tabulated $t$ and $F$ values at $\mathrm{P}=0.05$. 
Table (4): Assay results for the determination of Dipyridamole and Lamivudine in their different dosage forms by the proposed and Comparison methods. ${ }^{27,28}$

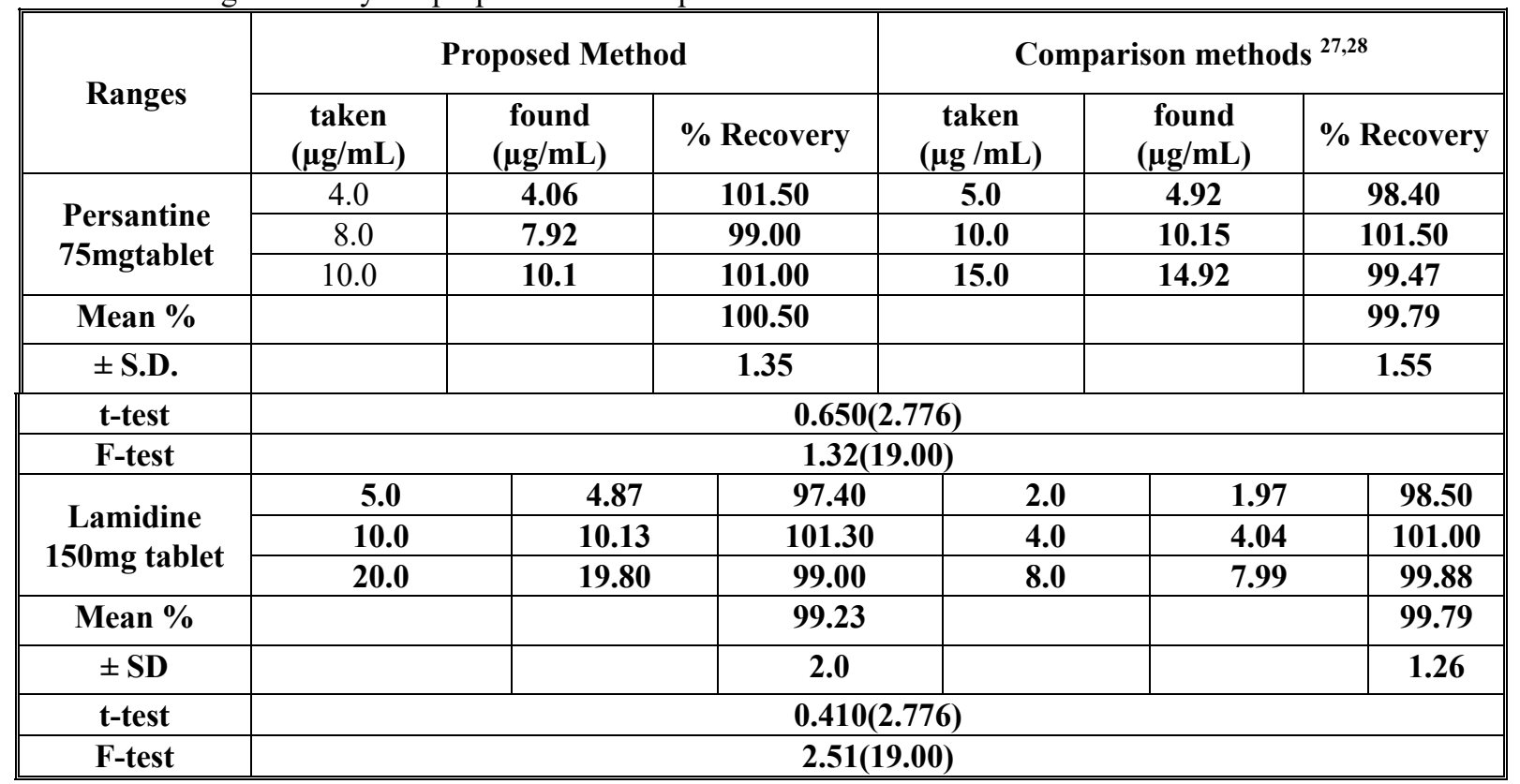

Each result is the average of three separate determinations.

The values between parentheses are the tabulated $t$ and $F$ values at $\mathrm{P}=0.05$.

\section{Conflict of interest}

The authors declare no conflict of interest Ethics

\section{Ethics statement: NA}

\section{Author contribution}

Authors FB and SA designed the study and wrote the protocol. SB performed the experimental work and statistical analysis. Authors FB and ME supervise the analyses of the study. Authors SA and SB wrote the first draft of the manuscript and managed literature searches. All authors read and approved the final manuscript

\section{Funding}

The work received no funding.

\section{REFERENCES}

1. Sweetman SC. Martindale: The Complete Drug Reference. Drug Monographs. London: Pharmaceutical press; 2011.

2. Kobayashi T, Sone K. Effect of dipyridamole on the blood flow in coronary aneurysms resulting from Kawasaki disease. Ann.Pediatr Cardiol. 1994; 15(6):263-7.
3. Saadat A, Pourbasheer E, Morsali S, Aalizadeh R. Simultaneous spectrophotometric determination of aspirin and dipyridamole in pharmaceutical formulations using the multivariate calibration methods. J. Curr. Pharm. Anal. 2018; 14(4):419-25.

4. El-Ragehy NA, Yehia AM, Hassan NY, Tantawy MA, Abdelkawy MJ. Chemometrics tools in detection and quantitation of the main impurities present in aspirin/dipyridamole extended-release capsules. J. AOAC Int. 2016; 99(4):948-56.

5. Hammud HH, El Yazbib FA, Mahrous ME, Sonji GM, Sonji NM. Stability-indicating spectrofluorimetric and RP-HPLC methods for the determination of aspirin and dipyridamole in their combination. Open Spectrosc J. 2008; 2: 19-28.

6. Sarakhman O, Pysarevska S, Dubenska L, Stanković DM, Otř́sal P, Planková A, Kianičková K, Švorc L. Voltammetric protocol for reliable determination of a platelet aggregation inhibitor dipyridamole on a bare miniaturized boron-doped diamond electrochemical sensor. J. Electrochem. Soc. 2019; 166(4):B219.

7. Li J, Li Y, Liu J, Liu M, Li K. Cloud-Point Extraction Coupled with High-Performance Liquid Chromatography for the Determination and Pharmacokinetic Study of Dipyridamole in Rat Plasma. J.Curr. Pharm. Anal. 2017; 13(5):481-7. 
8. Rao AS, Rao MK, Dadichand AS, Rao AP, Balaswami BJ. Development and validation of RP-HPLC method for assay of dipyridamole in formulations. J. Pharm. Sci. Res. 2016; 8(5):256.

9. Brunton LL, Lazo JS , Parker KL. Goodman and Gilman's: the Pharmacological Basis of Therapeutics. 11th ed. New York: McGraw-Hill Medical Publishing Division; 2006; 1288 - 1294.

10. Balint GA. Antiretroviral therapeutic possibilities for human immunodeficiency virus/acquired immunodeficiency syndrome. Pharmacol. Ther. 2001; 89(1):17-27.

11. Bhadauria RS, Gupta RK. Development and validation of UV Spectrophotometric method for simultaneous estimation of Lamivudine and Tenofovir Disproxil Fumarate in the combined dosage form. J. Drug Deliv. Ther. 2019; 9(4-s):1156-9.

12. Deepali G, Elvis M. UV Spectrophotometric Method for Assay of the Anti-Retroviral Agent Lamivudine in Active Pharmaceutical Ingredient in its Tablet Formulation. J. Young Pharm. 2010; 2(4):417-9.

13. Sonawane P, Panzade P, Kale M. Simultaneous estimation of lamivudine and tenofovir disoproxil fumarate in bulk and combined pharmaceutical dosage form by HPLC method. Asian J. Biomed. Pharm.Sci.2013; 3(16):27.

14. Noorbasha K, Nurbhasha S. A new validated stability-indicating RP-HPLC method for simultaneous quantification of dolutegravir and lamivudine in bulk and pharmaceutical dosage form. Future J. Pharm. Sci. 2020; $6(1): 1-10$.

15. Sekar R, Azhaguvel S. Simultaneous determination of HIV-protease inhibitors lamivudine and zidovudine in pharmaceutical formulations by micellar electrokinetic chromatography. J. Pharm. Biomed. Anal. 2005; 39(3-4):653-60.

16. Gras A, Yegles M, Karasi J-C, Schmit J-C, Seguin-Devaux C, Schneider S. Simultaneous quantification of zidovudine, stavudine, lamivudine and nevirapine by Micellar Electrokinetic Capillary Chromatography. Annales de Toxicologie Analytique. 2012; 24(4): 177-183.

17. Ahmed H, El-Shabrawy Y, Barseem A, Belal F. The use of complex formation approach for spectroscopic analysis of certain oral hypoglycemic with Eosin Y. Microchem. J. 2019; 149: 104054.
18. Walash MI, Rizk MS, Eid MI, Fathy ME. Spectrophotometric determination of four macrolide antibiotics in pharmaceutical formulations and biological fluids via binary complex formation with eosin and spectrophotometry. J. AOAC Int. 2007; 90(6):1579-87.

19. Omar MA. Spectrophotometric and spectrofluorimetric determination of certain diuretics through ternary complex formation with eosin and lead (II). J. Fluoresc. 2010; 20(1):275-81.

20. Dawson RMC, Elliott DC, Elliott WH, Jones KM. Data for biochemical research.3rd ed. pp 580. Oxford:Oxford Science Publications, OUP;1986. $£ 35 / \$ 59$ ISBN 0-19-855358-7.

21. Chernov'yants M, Podgornaya E, Chernyshev A, Metelitsa A, Knyazhanskii MJ. Identification and extraction - spectrophotometric or extraction-fluorimetric determination of organic nitrogen-containing triiodides, new biologically active compounds. J. Anal. Chem. .2000; 55(3):245-8.

22. El Walily AFM, Belal SF, Bakry RS. Spectrophotometric and spectrofluorimetric estimation of ciprofloxacin and norfloxacin by ternary complex formation with eosin and palladium (II). J. Pharm. Biomed. Anal.1996; 14(5):561-9.

23. El-Enany N. Spectrophotometric determination of gliclazide in pharmaceuticals and biological fluids through ternary complex formation with eosin and palladium (II). Farmaco .2004; 59(1):63-9.

24. El-Brashy AM, Metwally ME-S, El-Sepai FA. Spectrophotometric determination of some fluoroquinolone antibacterials by binary complex formation with xanthene dyes. Farmaco. 2004; 59(10):809-17.

25. Harvey D. Modern analytical chemistry. Boston: McGraw-Hill Companies,Inc; 2000.

26. ICH ,Q2(R1): Validation of analytical procedures: Text and Methodology.Geneva: International Conference on Harmonization; 2005.

27. The United States Pharmacopeia. 34th and The National Formulary 29th. USA: Rockville, MD; 2011.

28. Chowdary KPR. Development and validation of UV spectrophotometric method for lamivudine in comparison to HPLC methods .World J. Pharm. Res. 2015; 960-9. 
29. Miller JN, Miller JC. Statistics and chemometrics for analytical chemistry. vol 107-149. Harlow: Pearson Education Limited; 2005 